\title{
Genetic diversity assessment of Soybean germplasm accessions using pod shattering-related SSR markers
}

\author{
*Komal Ramchandra Pawar ${ }^{\text {ab }}$, A. M. Dethe ${ }^{\mathrm{a}}$, Rohini Manchare ${ }^{\mathrm{a}}$, \\ Manisha Dhanshetty ${ }^{b}$ \\ a. Vasantrao Naik Marathwada Krishi Vidyapeeth, Parbhani, India, 431402. \\ b ICAR-National Research Centre for Grapes, India, 412307. \\ *Corresponding author:komalpawar993@gmail.com
}

\begin{abstract}
:
The present investigation was carried out to characterize and validate the SSR markers linked to pod shattering trait at molecular-level in a given novel soybean germplasm during 2016-17. Efforts were made to study the DNA polymorphism via SSR markers linked to shattering in the given set of soybean accessions. The SSR markers conditioning the pod dehiscence yielded $100 \%$ polymorphism with corresponding 596 amplicons. PIC value ranged between 0.056 (Satt350) to 0.913(SRM0) with an average PIC value of 0.734 per primer. During this study, unique alleles were found for resistant genotypes (Satt244163) and highly susceptible genotypes (SRM1 507), which can be directly advocative for identification of resistant and susceptible genotypes and also to generate mapping population towards fine mapping of these ' $q P D H$ ' QTLs in soybean functional genomics.
\end{abstract}

Key words: $\quad$ Soybean, Germplasm, Pod shattering resistance, SSR, qPDH, QTL, PIC

\section{Introduction:}

Soybean (Glycine max (L.) Merr.) is the cheapest source of proteins and fats; hence it is called as 'Poorman's meat'. The soybean is a species of legume, native to East Asia and widely grown for its edible seeds. The cultivated soybean, is a member of the family Leguminacae. Soybean is an ancient polyploid with twenty chromosome pairs $(2 n=40)$. Pod shattering is a naturally preferred means of evolution, so that soybean can better produce more offspring's and is still commonly observed in the wild soybean species. Pod shattering of soybean refers to the trait of mature pods opening along the dorsal or ventral sutures to release the soybean seeds (Thakare et al., 2017).

Yield loss is the major issue occurs due to pod shattering when it is performing mechanically. The extent of yield loss due to pod shattering in soybean may ranges from 34 to $99 \%$ depending upon delayed harvesting period and environmental conditions (Agrawal et al., 2003). Fully mature pods of soybean are extremely sensitive to opening, resulting in seed loss. This majorly seen in susceptible varieties, prior to harvest due to disturbance of canopy by wind or during harvesting as the harvesting equipment, leading to seed losses of $50-100 \%$ (Bhor et al., 2014). So, Mechanical pod shattering of soybean is one of the major obstacles during harvesting by machines therefore, a high degree of tolerance to pod shattering is 
essential. Knowledge of the genetic mechanisms underlying pod shattering will facilitate breeding of shattering-resistant varieties and avoid this issue of mechanical pod shattering. The use of molecular markers, like simple sequence repeat (SSR), and restriction fragment length polymorphism (RFLP) provides a powerful tool for the analysis of plant genome structure and function. The markers density of SSRs and RFLPs on molecular maps makes them useful for genetic research purposes ranging from the detection of quantitative trait loci (QTL) to map-based cloning of agronomically important genes (Shoemaker and Specht, 1995).

Recently the complete soybean genome sequence was released (Schmutz et al., 2010). In case of soybean, it has been suggested that, pod shattering is controlled by two to four genes (Caviness, 1969; Tsuchiya, 1987). Among them, a single recessive gene, shl, is believed to control tolerance to the pod shattering (Halvankar and Patil, 1993). A major QTL for PD tolerance on LG J and minor QTLs on LG D1b, E and L have been reported (Bailey et al., 1997). It is necessary to validate the $q P D H$ linked markers in diverse genetic backgrounds. On this context, the present study was undertaken to characterize, identify selected soybean genotypes and validate the SSR markers for pod shattering in elite soybean genotypes.

\section{Experimental Details:}

\section{Seed material (Genotypes)}

The soybean genotypes for present study were obtained from the germplasm maintained at Soybean Research Station, VNMKV, Parbhani (MS). Around 35 genotypes including a check for highly shattering trait were selected along with advanced lines and improved varieties for the present investigation (Table 1).

\section{Evaluation of SSR markers associated with pod shattering}

In the present investigation, SSR primers, which were preselected (Grant et al., 2010; Bailey et al., 1997; Kang et al., 2009 and SoyBase) and further used for screening the given set of germplasm towards validation study.

\section{DNA extraction and SSR analysis}

Genomic DNA was extracted from the leaves of 15-days-old seedlings of 35 soybean genotypes grown in glasshouse following the Cetyltrimethyl ammonium bromide (CTAB) method with some modifications described by Doyle and Doyle (1987). The quality and quantity of isolated DNA was determined by agarose gel electrophoresis. Determination of quantity of isolated DNA was done by spectrophotometer (Hitachi-U2900) ${ }^{\mathrm{TM}}$.

\section{Screening with SSR primers linked to pod shattering in soybean}

The sequences of nineteen primers used in this study were obtained from the SoyBase $^{\odot}$ and available literature. Amplification reaction mixture was prepared in sterile 0.2 $\mathrm{ml}$ thin walled flat capped PCR tubes. The polymerase chain reaction was carried out in Eppendorf thermal cycler using 19 SSR markers. DNA was amplified by PCR using reaction mixture of $20 \mu \mathrm{l}$ containing DNA $25 \mathrm{ng} ; 10 \mathrm{X}$ Taq assay buffer; $10 \mathrm{mM} \mathrm{dNTPs} ; 25 \mathrm{mM}$ 
$\mathrm{MgCl} 2$ and $5 \mu \mathrm{M}$ each of forward and reverse primers (Table 2). Cycling parameters were initial denaturation at $94^{\circ} \mathrm{C}$ for $5 \mathrm{~min}$, denaturation at $94^{\circ} \mathrm{C}$ for $30 \mathrm{~s}$, primer annealing 42 $60^{\circ} \mathrm{C}$ for $50 \mathrm{~s}$, extension $72{ }^{\circ} \mathrm{C}$ for $1 \mathrm{~min}$, final extension $72^{\circ} \mathrm{C}$ for $10 \mathrm{~min}$, and hold at $4^{\circ} \mathrm{C}$ for $\alpha$. Steps from denaturation to final extension were repeated for 35 times for amplification of DNA. After completion of amplification, PCR products were stored at $-20^{\circ} \mathrm{C}$. The PCR products were resolved on $2.0 \%$ Agarose gel in $1 \mathrm{X}$ TAE buffer at $100 \mathrm{~V}$ for $2.0 \mathrm{hr}$. The gel was stained by Ethidium Bromide $(10 \mathrm{mg} / \mathrm{ml})$. After electrophoresis the photograph of gel was taken on a gel documentation system (Alphaimager ${ }^{\mathrm{TM}} 2200$ ). The PCR amplified products size was measured by using LabImage 1D L315 - Kapelan Bio-Imaging software.

\section{Scoring and data analysis}

Each amplification product as a dominant expression was considered as SSR marker and was scored across all the samples. Bands were scored as present (+/1) or absent (-/0). Molecular weights of the bands were estimated by using 100bp DNA ladder (GENEX) as standard. All amplifications were repeated at least twice and only reproducible bands were considered for analysis. The data was used for similarity based analysis using the programme NTSYS-pc ${ }^{\odot}$ (Version 2.02i) developed by Rohlf, 2000.

Similarity coefficients were used to construct UPGMA (unweighted pair group method with average) to generate dendrogram. Genetic similarity values based on Jaccard's coefficients were converted into genetic distance by subtracting similarity index (matrix) value from unity.

$$
\mathrm{GD}=1-\mathrm{SI}
$$

The polymorphic percentage of the obtained bands was calculated by using following formula,

Polymorphism $\%=$ (Number of polymorphic bands $/$ Total bands) $\mathrm{X} 100$

Further, the same data were used for Principal Coordinate Analysis (PCoA) using Eigen vectors to generate 2-dimensional and 3-dimensional scaling scatter plots by NTSYS-pc ${ }^{\odot}$ (Version 2.02i).

\section{Polymorphism Information Content}

Polymorphism Information Content (PIC) value were calculated as per formula developed by Powell et al. (1996)

$$
P I C=1-\sum P_{i j}{ }^{2}
$$

Where, $\mathrm{P}_{\mathrm{ij}}$ is the frequency of $\mathrm{i}^{\text {th }}$ and $\mathrm{j}^{\text {th }}$ locus, summed across the entire locus over all lines.

\section{Result and discussion:}

In this study, the SSR markers used are described to be linked with pod shattering loci. Therefore, the persistence of this study was to validate these markers in different soybean 
accessions for their possible use in future breeding program for development of pod shattering tolerant genotypes

The quality of DNA was checked by using $0.8 \%$ agarose. The intact and bright quality bands indicated that there was no contamination of RNA and Protein. The purity and quantity of DNA was checked by using both O.D. $260 \mathrm{~nm}$ and $280 \mathrm{~nm}$ wavelength on spectrophotometer (Hitachi U-1900 ${ }^{\circledR}$ ).

A set of 19 pre-selected SSR primer pairs were used for initial screening to amplify DNA from these thirty-five soybean accessions to screen the candidate markers for pod shattering in soybean. Out of 19 SSR primers, only 16 were found to be polymorphic. It was detected that total of 38 alleles were amplified by these 16 primers and all alleles were found to be polymorphic. Thus, $100 \%$ polymorphism was detected in the given germplasm set during present investigation (Table 3).

Kang et al.,2009 reported that a single major QTL on linkage group J explained 46\% of phenotypic variation in pod dehiscence and four minor QTLs which showed epistatic interaction for pod dehiscence (Kang et al.,2009). They suggested that different breeding strategies would be required for controlling pod dehiscence depending on different genetic background and effective marker-assisted selection (MAS) for the major QTL qPDH1 may be used for minimizing soybean pod dehiscence. Yamada et al., 2009 showed the possible presence of a QTL on LG, A2 in a cross between Toyomusume (SS) and Harosoy (SR) (Yamada et al., 2009). These QTLs may be useful for fine-tuning of shattering resistance, since in some cases sound shattering resistance is essential hence shattering resistant cultivar could be established by pyramiding shattering resistance alleles at minor QTLs (Funatsukiet al., 2012).

The unique alleles specific for resistant accessions, cat2237B (primer Satt244 and allele Satt244163) (Fig. 5) and wild susceptible genotype Glycine soja (primer SRM1 and allele SRM1507) (Fig. 2) were observed in this study, which will be helpful for DNA fingerprinting and as an identity marker towards resistance and highly susceptible trait/ gene(s) controlling QTL in respect of pod shattering traits. Previously it is reported that, occurrence of unique alleles facilitated in the identification of such specific genotypes (Bisenet al., 2014). Such markers are extremely consistent in the establishment of genetic relatedness between the genotypes. Parallel results were also described by Jain et al.,1994, Srivastava et al., 2001 and Vinuet al., 2013 in different crop species (Jain et al.,1994; Srivastava et al., 2001; Vinuet al., 2013).

The polymorphism information content (PIC) values were calculated to find out the effectiveness of primers in distinguishing individual accession (Table 3). The polymorphic information content (PIC) values were ranged between 0.05 to 0.9 with an average PIC value of 0.734 per primer. The SSR primer, SRM0 revealed highest i.e. 0.913 PIC value followed by Satt244 (0.907), Satt166 (0.882) and Sat-342 (0.872); whereas the primer Satt350 revealed the lowest (0.056) PIC value (Table 3). All 16 primers were ranged between 0.05 and 0.91 for PIC values. 
Yamada et al., 2013 reported that in India, high levels of shattering resistance have become essential together in moderately humid and dry areas, due to growing trend of mechanical harvesting (Yamada et al., 2013). For that there is necessity to screen the Indian varieties for occurrence of $p d h l$ alleles. For case, $p d h l$ can be used to yield shattering resistant genotypes with various genetic backgrounds especially in the areas with a low $p d h 1$ frequency by the combined use of backcrossing and marker-assisted selection.

\section{Clustering analysis based on SSR markers}

The cluster analysis of the SSR marker data based on UPGMA using Jaccard's coefficient of similarity, showed a relatively narrow genetic background of indigenous germplasm accessions. Even though, the number of markers used in this study is comparatively less, they are able to form six distinct major clusters at an arbitrary cut-off of $0 \%$ similarity. Cluster-I was included 15 soybean accessions. In subcluster-Ic, non-shattering or resistant soybean accessions, MAUS32 and MAUS61 shared 90\% similarity with each other. Subcluster-Id having cat2134A accession was found to be outgrouped. Cluster-II included 6 accessions, while Cluster-III having 5 accessions. However, Cluster-IV possessed 3 accessions, out of which cat872B was outgrouped within it. Cluster-V also contained 5 soybean accessions of which cat2130B genotype was outgrouped. In this clustering analysis, it was observed the most distinct genotype was completely outgrouped wild accession Glycine soja which has not revealed any of similarity with all the remaining accessions (Fig. 17).

Moreover, the relationship among 35 promising soybean accessions were further observed and confirmed by the PCoA based on derived values of Jaccard's similarity coefficient. The two-dimensional and three-dimensional scatter plots envisaged that majority of groupings followed the same pattern as depicted in the dendrogram with minor differences. Consequently, it can be recommended that both UPGMA clustering and PCoA scaling should be performed for more precise genetic diversity analysis.

\section{Conclusion:}

The molecular information revealed by present investigation for pod shattering evaluation will be highly useful into future facilitation to soybean breeders to develop high yielding and hybrids through 'elite $\mathrm{x}$ elite crosses' to accumulate favorable genes involved various morphological and pod shattering tolerance traits by assisting them in the selection from such diverse soybean germplasm members, thus saving time, cost and labour during empirical soybean improvement.

\section{Acknowledgement}

Authors are thankful to Vasantrao Naik Marathwada Krushi Vidyapeeth, Parbhani and VDCOAB, Latur for providing facilities to conduct this research work and greatly acknowledges DBT for providing fund to carry out this work. 


\section{References:}

1. A.P. Agrawal, P.W. Basarkar, P.M. Salimath and S.A. Patil, Current Science, 82(10) (2002) 58.

2. A.P. Agrawal, P.M. Salimath, and S.A. Patil, Indian Journal of Genetics, 63(3) (2003) 265266.

3. M.A. Bailey, M.A.R Mian, T.E. Carter, D.A. Ashley, and H.R. Boerma, Journal of Heredity, 88 (1997) 152-154.

4. A. Bisen, D. Khare, P. Nair, and N. Tripathi, Physiology and Molecular Biology of Plants, (2014).

5. T.J. Bhor, V.P. Chimote, and M.P. Deshmukh, Electronic journal of plant breeding, 5(4) (2014) 671-676.

6. C.E. Caviness, Crop science, 9 (1969) 207-209.

7. J.J. Doyle, and J.V. Doyle,. Phytochemical bulletin, 19 (1987) 810-815.

8. H. Funatsuki, M. Hajika, T. Yamada, M. Suzuki, S. Hagihara, Y. Tanaka, S. Fujita, M. Ishimoto, and K. Fujino, Breeding science, 61 (2012) 554-558.

9. G.B. Halvankar, and V.P. Patil, Journal of Maharashtra Agricultural University, 18(1) (1993) 46-49.

10. A. Jain, S. Bhatia, S.S. Banga, S. Prakash, and M. Lakshmikumaran, Theoretical and Applied Genetics, 88 (1994) 116-122.

11. S.T. Kang, M. Kwak, H.K. Kim, M.G. Choung, W.Y. Han, I.Y. Baek, M.Y. Kim, K. Van, and S.H. Lee, Euphytica, 166 (2009) 15-24.

12. F.J. Rohlf, Applied Biostatics, New York, 2000.

13. J. Schmutz, S.B. Cannon, J. Schlueter, J. Ma, T. Mitros, W. Nelson, D.L. Hyten, Q. Song, J.J. Thelen, and J. Cheng, Nature, 463 (2010) 178-183.

14. A. Srivastava, V. Gupta, D. Pental, and A.K. Pradhan, Theoretical and Applied Genetics, 102 (2001) 193-199.

15. R.C. Shoemaker, and J.E. Specht, Crop Science, 35 (1995) 436-446.

16. T. Tsuchiya, The Japan Agricultural Research Quarterly, 21(1987) 166-176.

17. T. Yamada, H. Funatsuki, S. Hagihara, S. Fujita, Y. Tanaka, H. Tsuji, M. Ishimoto, K. Fujino, and M. Hajika, Breeding science, 59 (2009) 435-440.

18. T. Yamada, H. Funatsuki, S. Hagihara, S. Fujita, Y. Tanaka, H. Tsuji, M. Ishimoto, K. Fujino, and M. Hajika, Bull NARO Inst Crop. Sci.14 (2013) 13-22.

19. V. Vinu, N. Singh, S. Vasudev, D.K. Yadava, S. Kumar, S. Naresh, S.R. Bhat, and K.V. Prabhu, Revista de Biologia Tropical,61(4) (2013) 1919-1934.

20. D.S. Thakare, V.P. Chimote, M.Deshmukh,R. Rokade, and A. Aadsul, The Indian Society of Oilseeds Research, (2017) 15.

21. N.Vairam, BioScan, 13 (1) (2018) 215-218.

22. https://en.wikipedia.org/wiki/Soybean\#: :text=The\%20soybean $\% 2 \mathrm{C} \% 20$ soy $\% 20$ bean $\% 2 \mathrm{C} \% 20 \mathrm{or}$,and $\% 20 \mathrm{tofu}$ \%20skin\%20are\%20made

23. www.soybase.org/search/index.php?qtl=shattering 
Table 1 List of Soybean germplasm accessions used for the present investigation

\begin{tabular}{|c|c|c|c|}
\hline Sr.No. & Accessions & Sr.No. & Accessions \\
\hline 1. & MAUS 01 & 19. & Cat 1979 A \\
\hline 2. & MAUS 02 & 20 . & Cat 1987 \\
\hline 3. & MAUS 32 & 21. & Cat $2130 \mathrm{~B}$ \\
\hline 4. & MAUS 61 & 22. & Cat $2134 \mathrm{~A}$ \\
\hline 5. & MAUS 162 & 23. & RI 60 Cat 2205 B \\
\hline 6. & Cat 872 B & 24 & Cat 3442 \\
\hline 7. & Cat $2115 \mathrm{~B}$ & 25. & Cat 3443 \\
\hline 8. & Cat $2237 \mathrm{~B}$ & 26. & Cat 3447 \\
\hline 9. & Cat 3458 & 27. & Cat 3502 \\
\hline 10. & Cat 3459 & 28 & Cat 700A \\
\hline 11. & Cat 3468 & 29. & Cat $489 \mathrm{~A}$ \\
\hline 12. & Harder & 30 & Cat 492A \\
\hline 13. & JS 93-05 & 31. & MAUS 158 \\
\hline 14. & JS 335 & 32. & AGS 25 \\
\hline 15. & G 11 & 33. & PP 6 \\
\hline 16. & VLS 75 & 34. & LEE 54 \\
\hline 17. & Cat $1641 \mathrm{~A}$ & 35. & Glycine soja \\
\hline 18. & Cat $1921 \mathrm{~A}$ & & \\
\hline
\end{tabular}

Table 2 Composition of PCR reaction mixture

\begin{tabular}{|l|c|c|}
\hline \multicolumn{1}{|c|}{ Reagents } & Stock Concentration & Volume $(\boldsymbol{\mu l})$ \\
\hline $\begin{array}{l}\text { PCR buffer B (100 mM Tris (pH 9.0), 500 } \\
\text { mM KCl and 0.1\% gelatin) }\end{array}$ & $10 \mathrm{X}$ & 2.0 \\
\hline $\mathrm{MgCl}_{2}$ & $25 \mathrm{mM}$ & 1.7 \\
\hline dNTPs mix & $10 \mathrm{mM}$ & 2.0 \\
\hline Primer-forward & $5 \mu \mathrm{M}$ & 1.0 \\
\hline Primer-reverse & $5 \mu \mathrm{M}$ & 1.0 \\
\hline Taq DNA Polymerase & $3 \mathrm{unit} / \mu \mathrm{l}$ & 0.3 \\
\hline Template DNA & $25 \mathrm{ng} / \mu \mathrm{l}$ & 1.0 \\
\hline Ultrapure $\mathrm{H}_{2} \mathrm{O}$ & ---- & 11.0 \\
\hline Total volume of Cocktail & & $20 \mu \mathrm{l}$ \\
\hline
\end{tabular}


Table 3 DNA polymorphism by simple sequence repeat (SSR) markers

\begin{tabular}{|c|c|c|c|c|c|c|c|c|}
\hline $\begin{array}{l}\text { Sr. } \\
\text { No. }\end{array}$ & $\begin{array}{c}\text { SSR } \\
\text { Primer } \\
\text { code }\end{array}$ & $\begin{array}{c}\text { Total No. } \\
\text { of } \\
\text { amplicons }\end{array}$ & $\begin{array}{l}\text { Total No. of } \\
\text { Polymorphic } \\
\text { bands }\end{array}$ & $\begin{array}{l}\text { Average } \\
\text { No. of } \\
\text { bands/ } \\
\text { genotype }\end{array}$ & $\begin{array}{l}\text { Total } \\
\text { No. } \\
\text { of } \\
\text { loci } \\
(T)\end{array}$ & $\begin{array}{c}\text { No. of } \\
\text { Polymor- } \\
\text { phic loci }\end{array}$ & $\begin{array}{c}\% \\
\begin{array}{c}\% \\
\text { Polymor- } \\
\text { phism }\end{array} \\
\text { P/T x100 }\end{array}$ & PIC \\
\hline & & & & & & & & \\
\hline 1 & SRMO & 31 & 31 & 0.89 & 3 & 3 & 100 & 0.913 \\
\hline 2 & SRM1 & 46 & 46 & 1.31 & 3 & 3 & 100 & 0.808 \\
\hline 3 & SRM2 & 27 & 27 & 0.77 & 2 & 2 & 100 & 0.851 \\
\hline 4 & satt166 & 48 & 35 & 1.37 & 4 & 4 & 100 & 0.882 \\
\hline 5 & Satt350 & 34 & 34 & 0.97 & 1 & 1 & 100 & 0.056 \\
\hline 6 & Satt215 & 55 & 55 & 1.57 & 2 & 2 & 100 & 0.383 \\
\hline 7 & Satt244 & 32 & 32 & 0.91 & 3 & 3 & 100 & 0.907 \\
\hline 8 & Satt243 & 28 & 28 & 0.80 & 2 & 2 & 100 & 0.840 \\
\hline 9 & Satt355 & 53 & 53 & 1.51 & 3 & 3 & 100 & 0.745 \\
\hline 10 & Satt409 & 41 & 41 & 1.17 & 3 & 3 & 100 & 0.848 \\
\hline 11 & Sat_342 & 25 & 25 & 0.71 & 2 & 2 & 100 & 0.872 \\
\hline 12 & Sat_273 & 29 & 29 & 0.83 & 2 & 2 & 100 & 0.828 \\
\hline 13 & Satt285 & 34 & 34 & 0.97 & 2 & 2 & 100 & 0.764 \\
\hline 14 & Sat_396 & 27 & 27 & 0.77 & 2 & 2 & 100 & 0.851 \\
\hline 15 & Satt385 & 32 & 32 & 0.91 & 2 & 2 & 100 & 0.791 \\
\hline 16 & Satt126 & 54 & 54 & 1.54 & 2 & 2 & 100 & 0.405 \\
\hline & Average & 37.25 & 37.25 & 1.06 & 2.37 & 2.37 & 100.00 & 0.734 \\
\hline
\end{tabular}




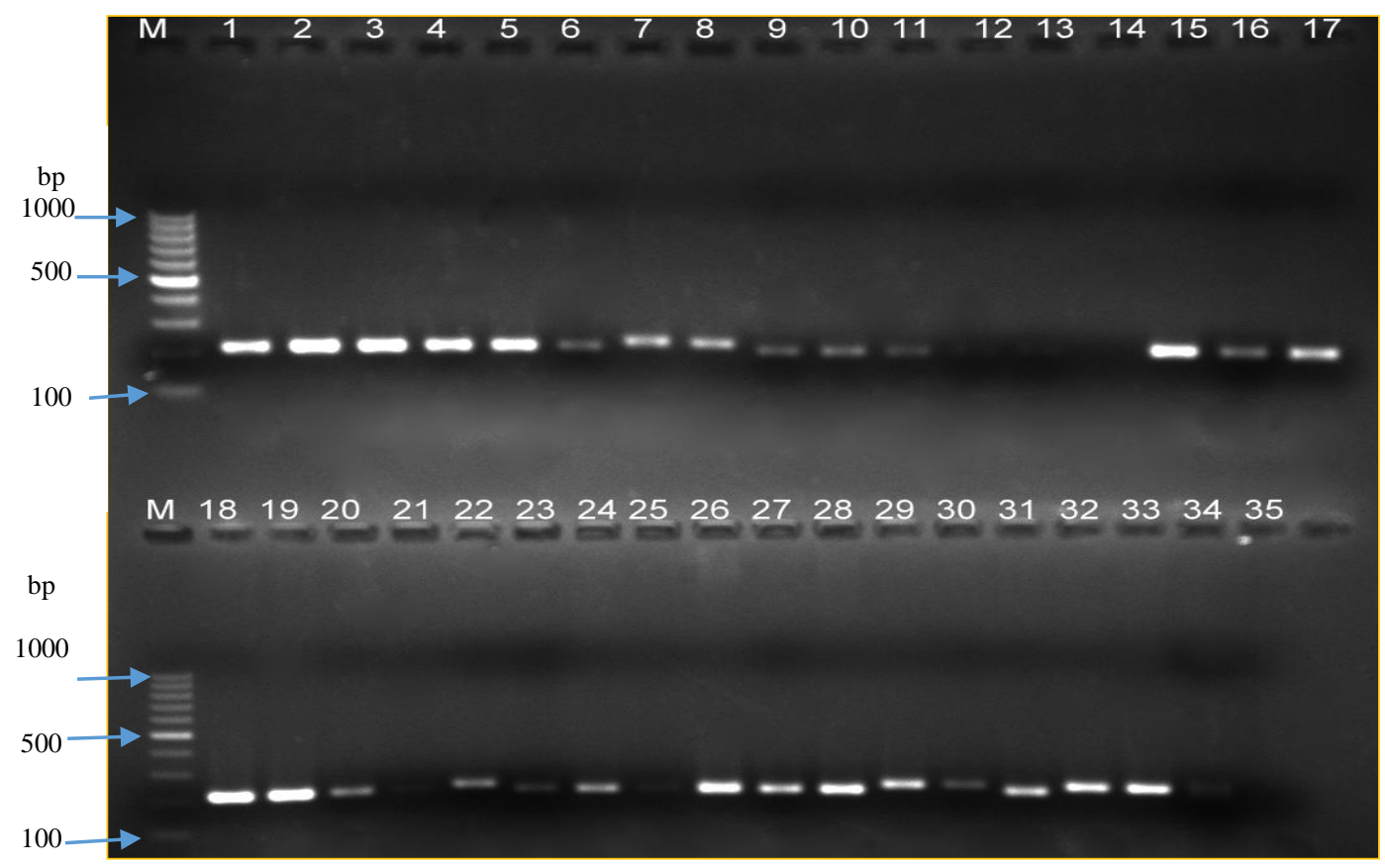

Figure 1: SSR Profile of 35 soybean accessions obtained with primer SRMO

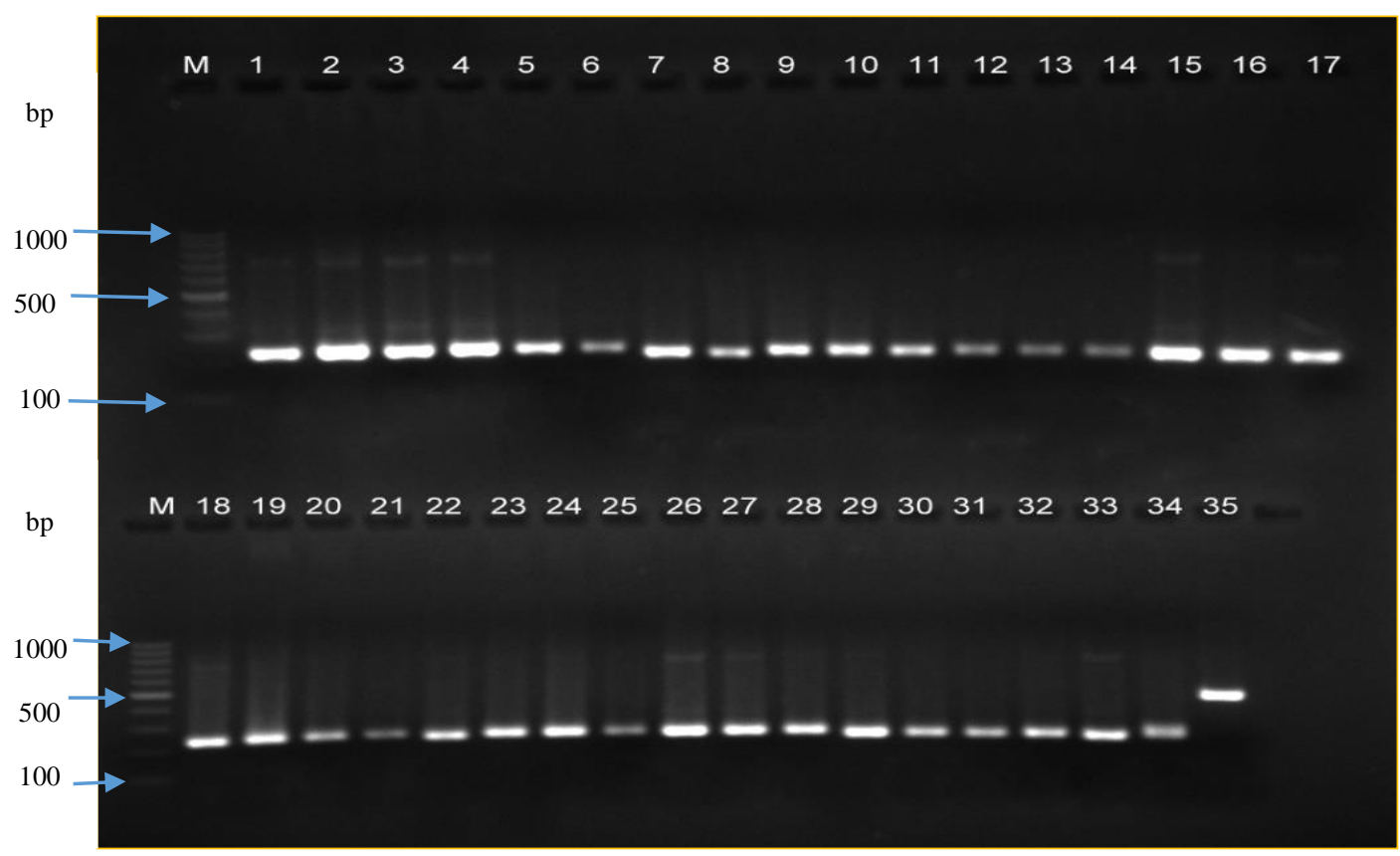

Figure 2: SSR Profile of 35 soybean accessions obtained with primer SRM1

\begin{tabular}{|l|l|l|l|l|l|l|}
\hline 1.MAUS 01 & 6.cat872B & 11.cat34681 & 16.VLS-75 & 21.cat2130B & 26.cat3447 & 31.MAUS158 \\
\hline 2.MAUS02 & 7.cat2115B & 12.Harder & 17.cat1641A & 22.cat2134A & 27.cat3502 & 32.AGS-25 \\
\hline 3.MAUS32 & 8.cat2237B & 13.JS-93-05 & 18.cat1921A & 23.RI60cat2205B & 28.cat700A & 33.PP-6 \\
\hline 4.MAUS61 & 9.cat3458 & 14.JS-335 & 19.1979A & 24.cat3442 & 29.cat489A & 34.LEE-54 \\
\hline 5.MAUS162 & 10.cat3459 & 15.G-11 & 20.cat1987 & 25.cat3443 & 30.cat492A & 35.Glycine soja \\
\hline
\end{tabular}

M - 100 bp DNA ladder Lanes: 1 to 35 (Soybean accessions) 


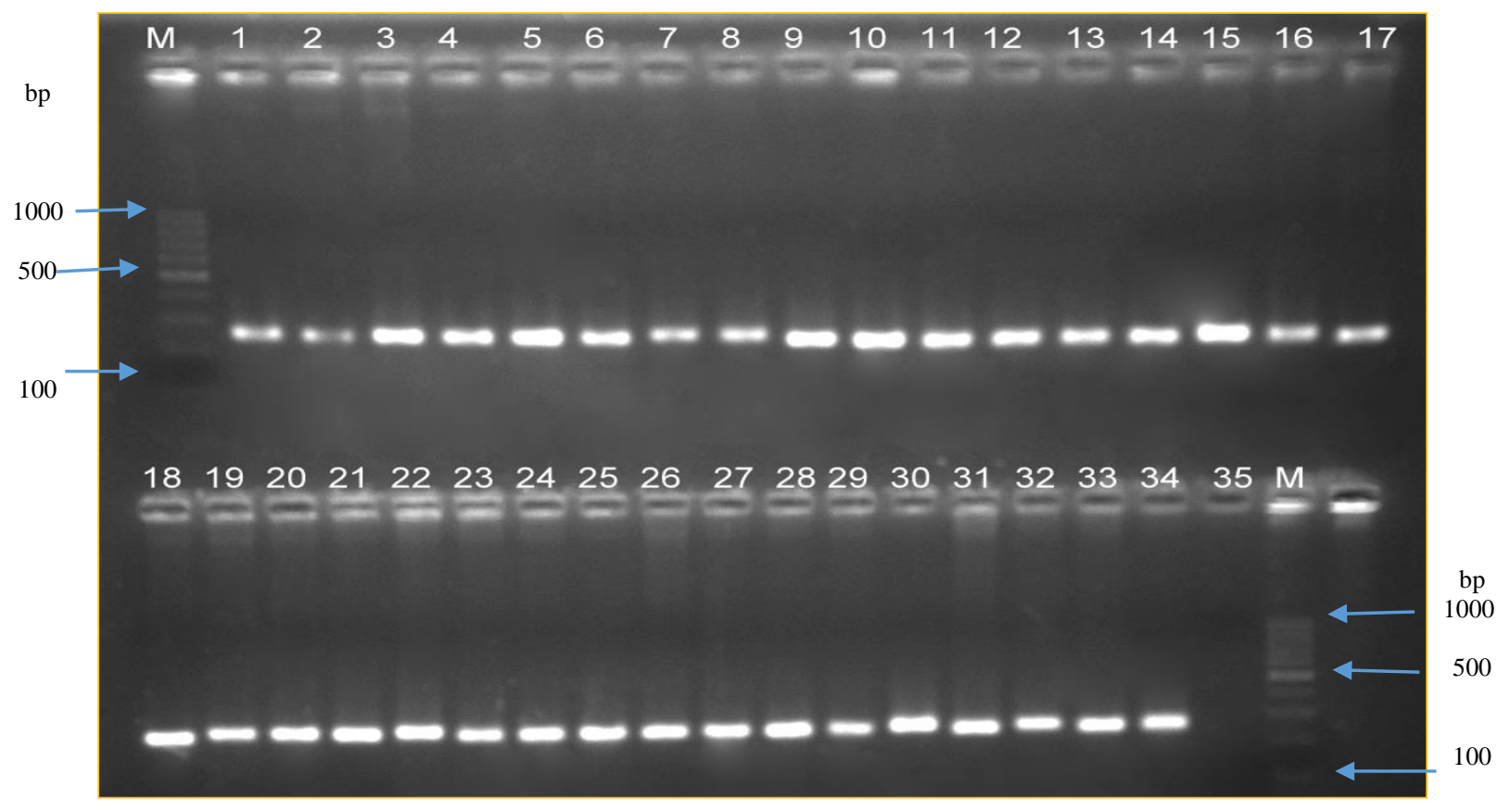

Figure 3: SSR Profile of 35 soybean accessions obtained with primer Satt350

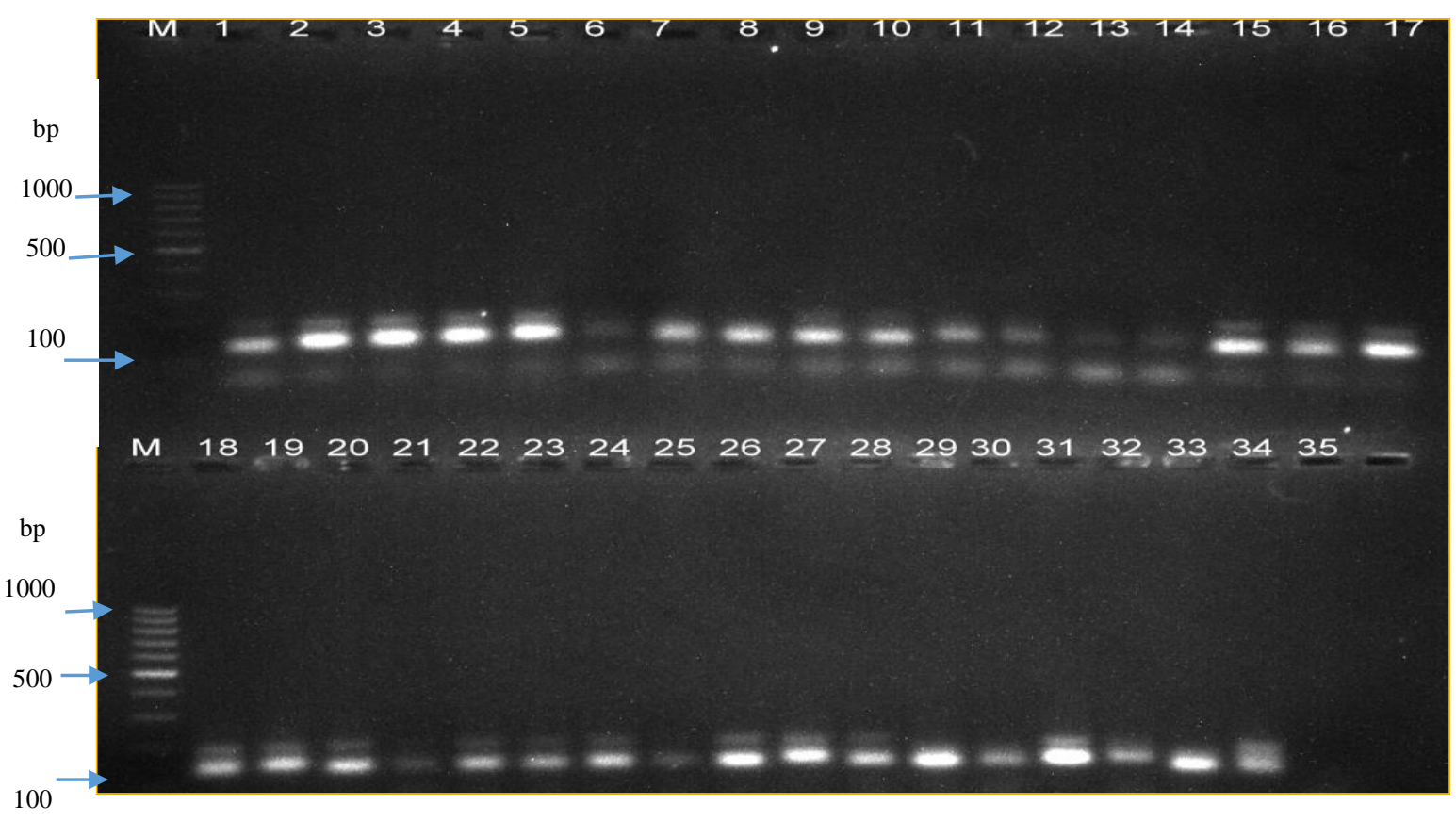

Figure 4: SSR Profile of 35 soybean accessions obtained with primer Satt215

\begin{tabular}{|c|c|c|c|c|c|c|}
\hline 1.MAUS 01 & 6.cat872B & 11.cat34681 & 16.VLS-75 & 21.cat2130B & 26.cat3447 & 31.MAUS158 \\
\hline 2.MAUS02 & 7.cat2115B & 12.Harder & 17.cat1641A & 22.cat2134A & 27.cat3502 & 32.AGS-25 \\
\hline 3.MAUS32 & 8.cat2237B & 13.JS-93-05 & 18.cat1921A & 23.RI60cat2205B & 28.cat700A & 33.PP-6 \\
\hline 4.MAUS61 & 9.cat3458 & 14.JS-335 & 19.1979A & 24.cat 3442 & 29.cat489A & 34.LEE-54 \\
\hline 5.MAUS162 & 10.cat3459 & 15.G-11 & 20.cat1987 & 25.cat3443 & 30.cat492A & 35.Glycine soja \\
\hline & & \multicolumn{2}{|c|}{ M - 100 bp DNA ladder } & Lanes: 1 to 35 (So. & an accession & \\
\hline
\end{tabular}




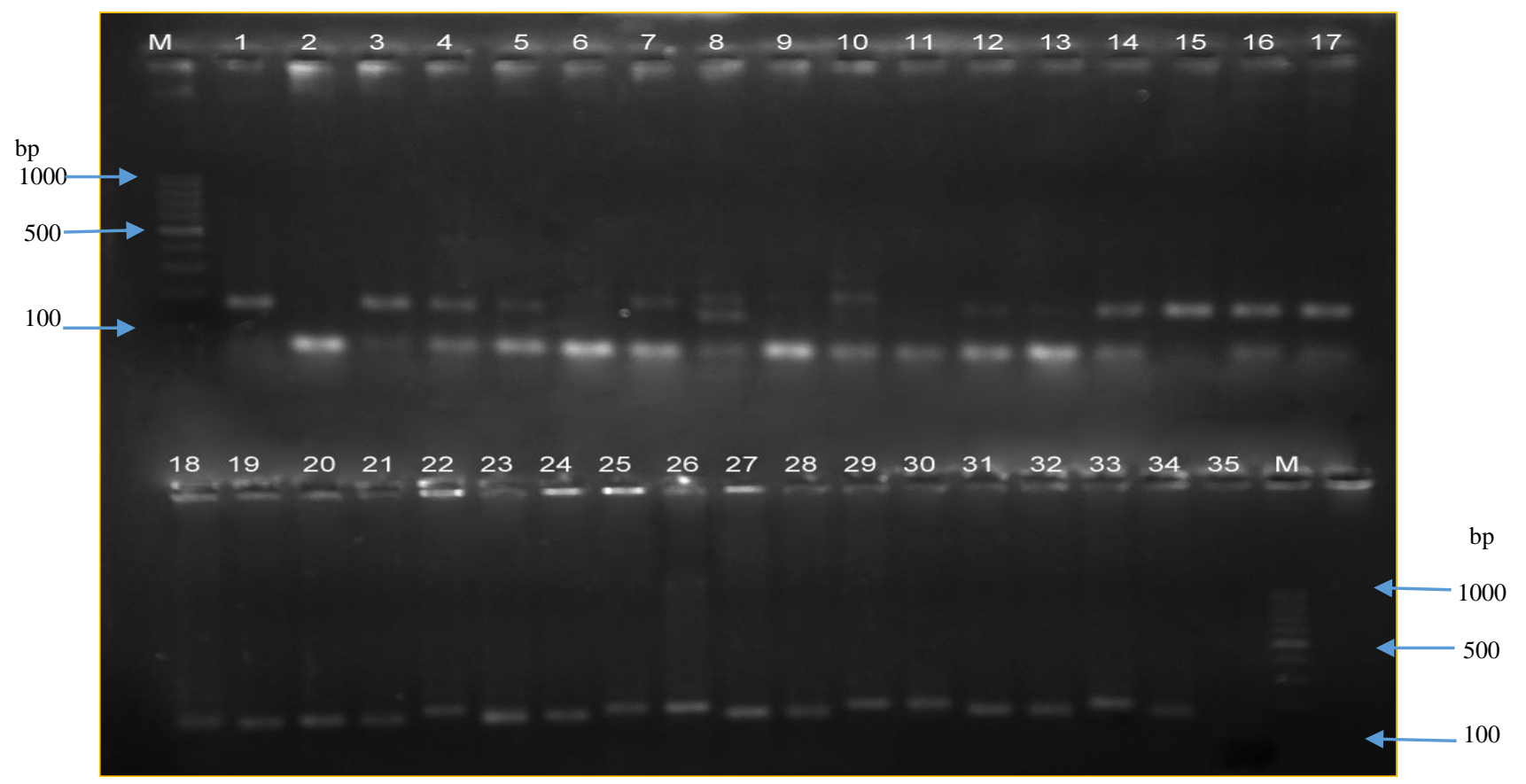

Figure 5: SSR Profile of 35 soybean accessions obtained with primer Satt244

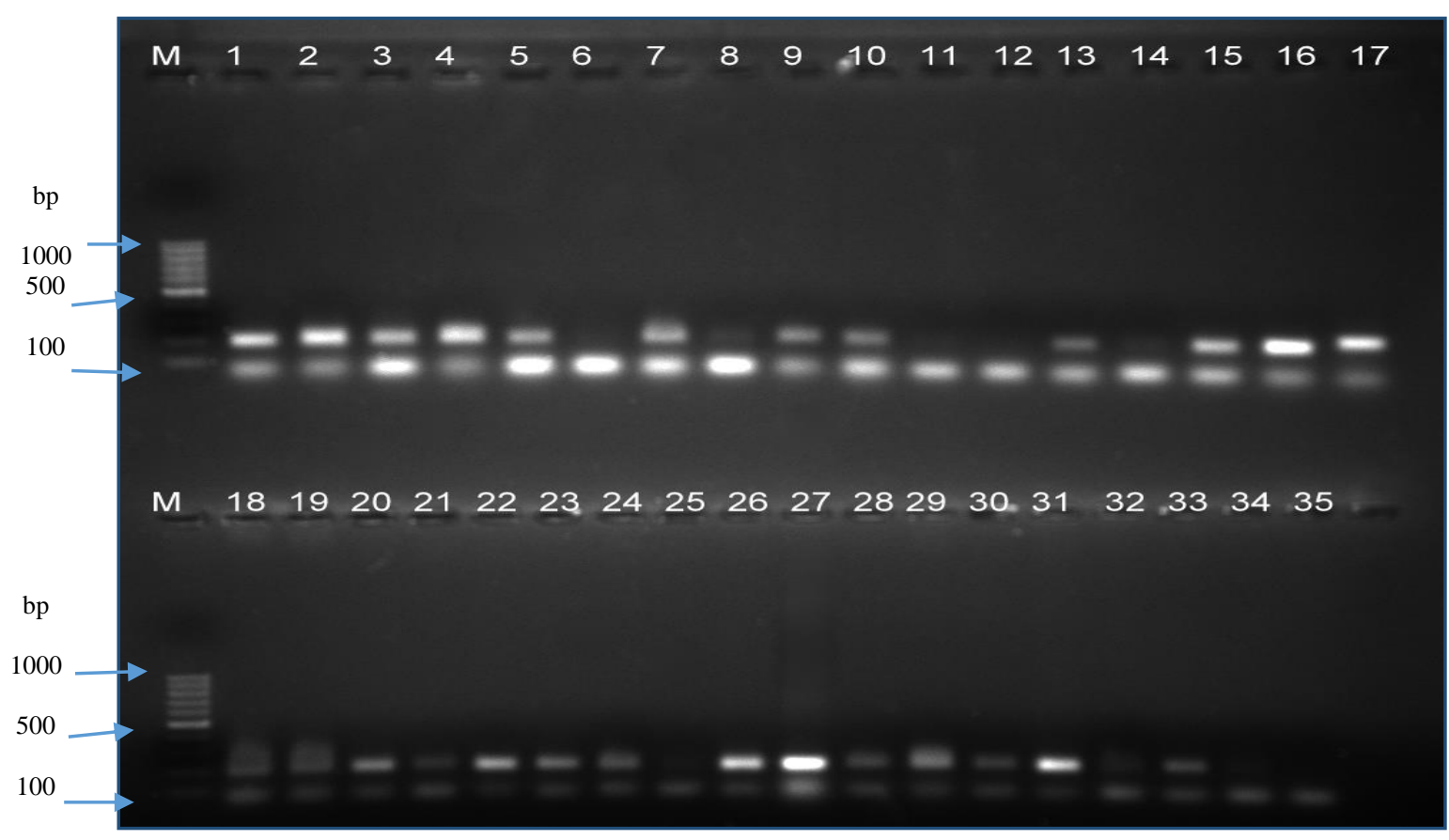

Figure 6: SSR Profile of 35 soybean accessions obtained with primer Satt243

\begin{tabular}{|l|l|l|l|l|l|l|}
\hline 1.MAUS 01 & 6.cat872B & 11.cat34681 & 16.VLS-75 & 21.cat2130B & 26.cat3447 & 31.MAUS158 \\
\hline 2.MAUS02 & 7.cat2115B & 12.Harder & 17.cat1641A & 22.cat2134A & 27.cat3502 & 32.AGS-25 \\
\hline 3.MAUS32 & 8.cat2237B & 13.JS-93-05 & 18.cat1921A & 23.RI60cat2205B & 28.cat700A & 33.PP-6 \\
\hline 4.MAUS61 & 9.cat3458 & 14.JS-335 & 19.1979A & 24.cat3442 & 29.cat489A & 34.LEE-54 \\
\hline 5.MAUS162 & 10.cat3459 & 15.G-11 & 20.cat1987 & 25.cat3443 & 30.cat492A & 35.Glycine soja \\
\hline
\end{tabular}

M - 100 bp DNA ladder Lanes: 1 to 35 (Soybean accessions) 


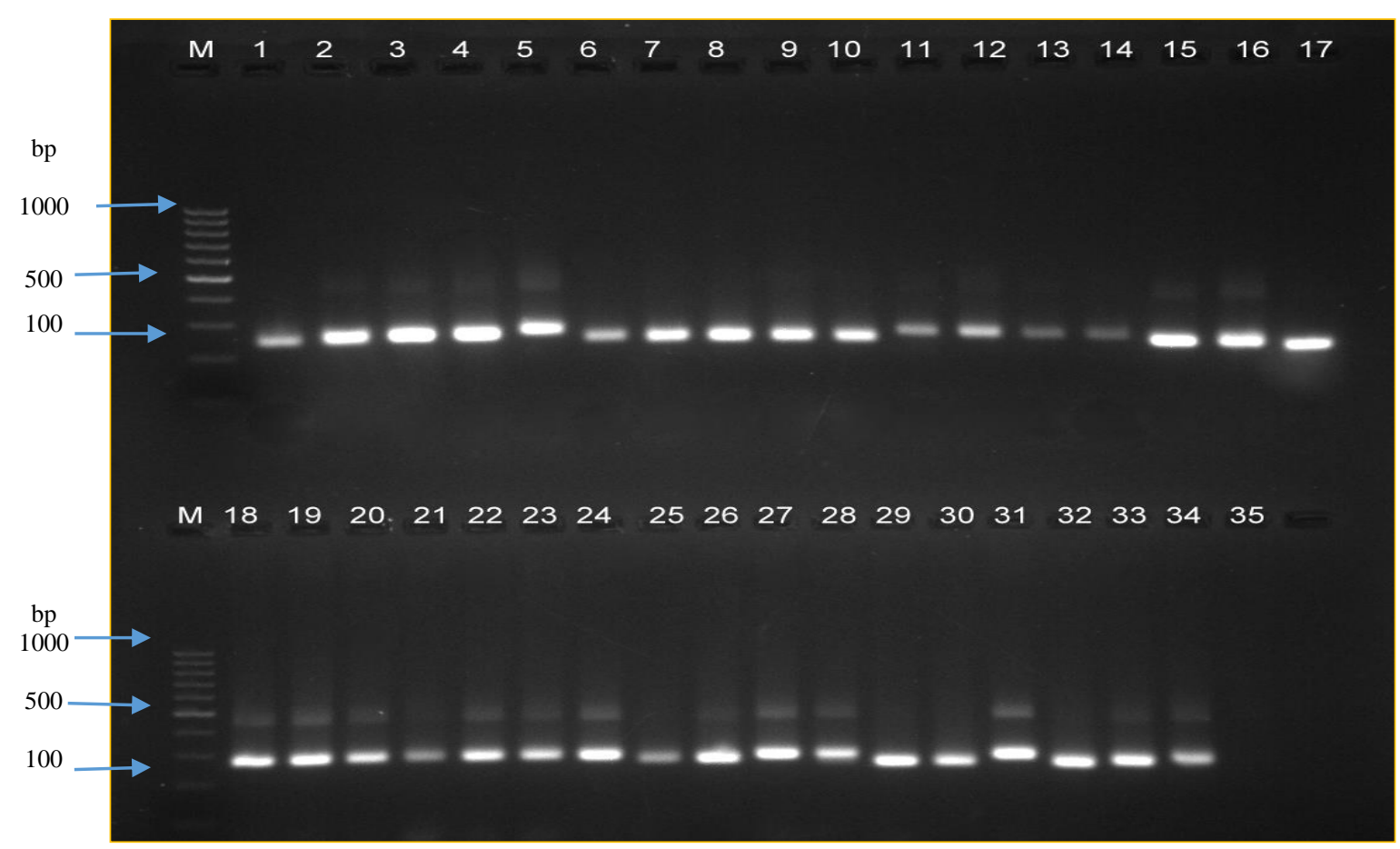

Figure 7: SSR Profile of 35 soybean accessions obtained with primer Satt355

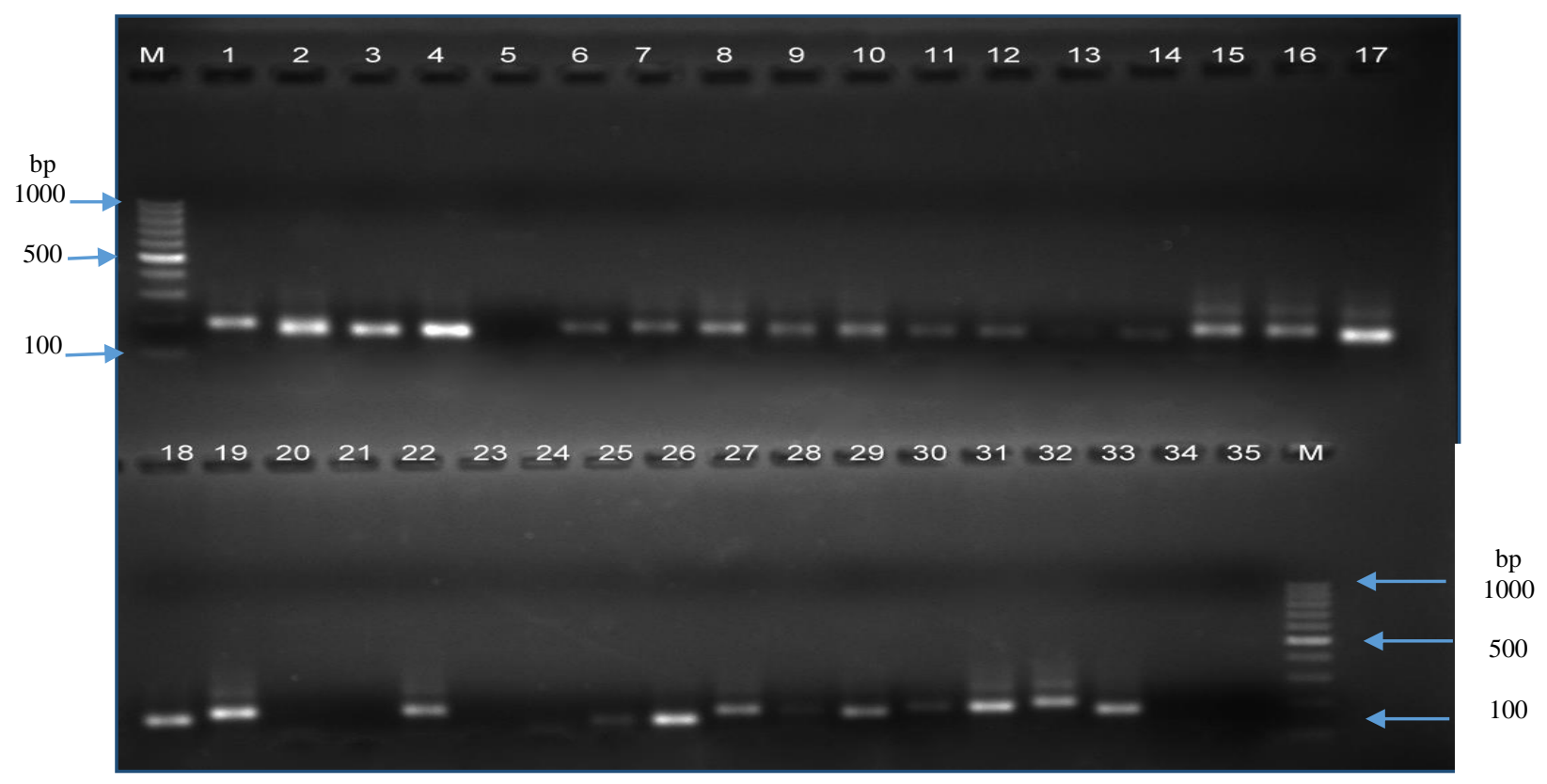

Figure 8: SSR Profile of 35 soybean accessions obtained with primer Satt409

\begin{tabular}{|l|l|l|l|l|l|l|}
\hline 1.MAUS 01 & 6.cat872B & 11.cat34681 & 16.VLS-75 & 21.cat2130B & 26.cat3447 & 31.MAUS158 \\
\hline 2.MAUS02 & 7.cat2115B & 12.Harder & 17.cat1641A & 22.cat2134A & 27.cat3502 & 32.AGS-25 \\
\hline 3.MAUS32 & 8.cat2237B & 13.JS-93-05 & 18.cat1921A & 23.RI60cat2205B & 28.cat700A & 33.PP-6 \\
\hline 4.MAUS61 & 9.cat3458 & 14.JS-335 & 19.1979A & 24.cat3442 & 29.cat489A & 34.LEE-54 \\
\hline 5.MAUS162 & $\mathbf{1 0 . c a t 3 4 5 9}$ & $\mathbf{1 5 . G - 1 1}$ & $\mathbf{2 0 . c a t 1 9 8 7}$ & 25.cat3443 & 30.cat492A & 35.Glycine soja \\
\hline
\end{tabular}

$$
\text { M - } 100 \text { bp DNA ladder Lanes: } 1 \text { to } 35 \text { (Soybean accessions) }
$$




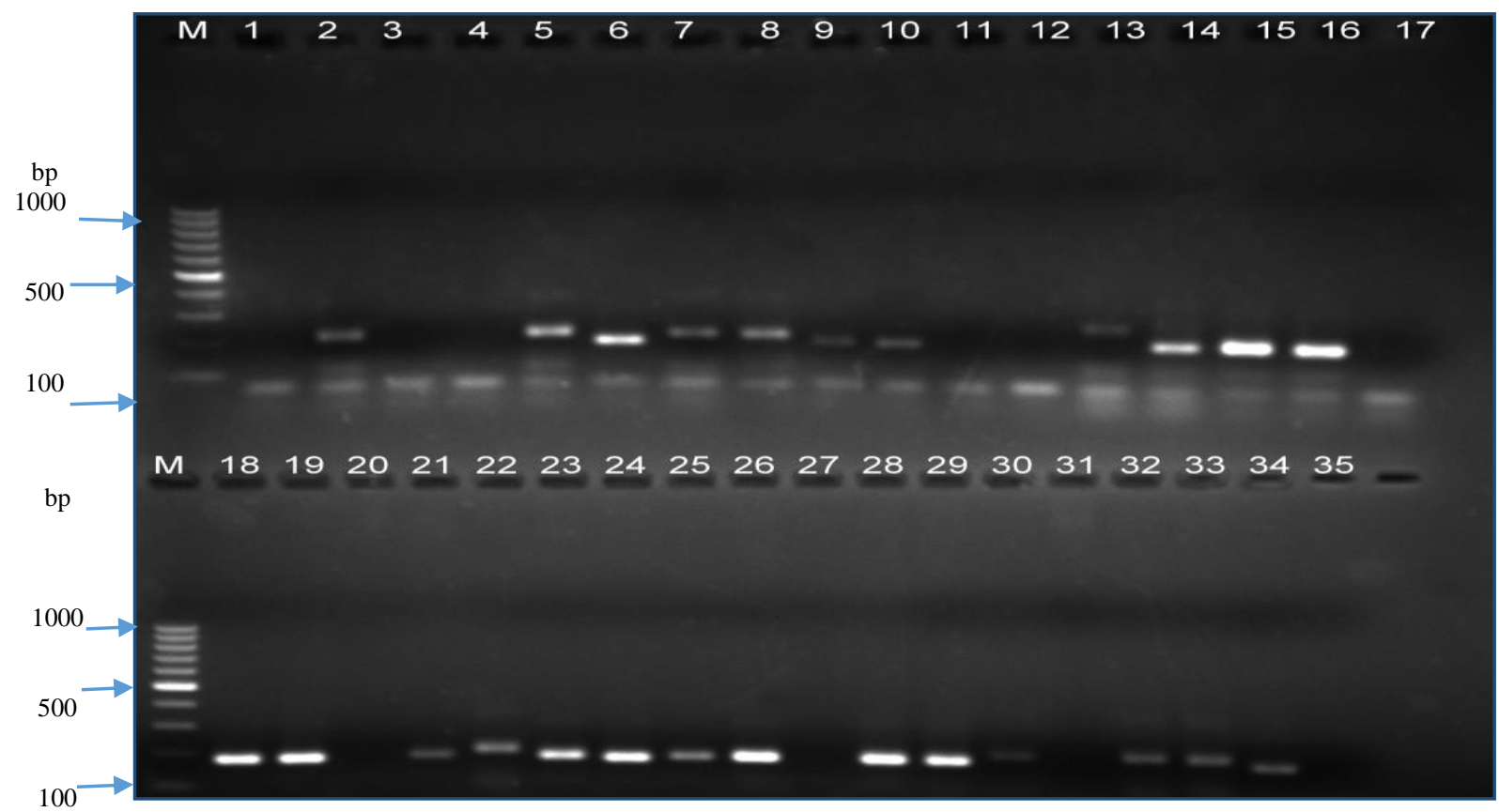

Figure 9: SSR Profile of 35 soybean accessions obtained with primer Sat.342

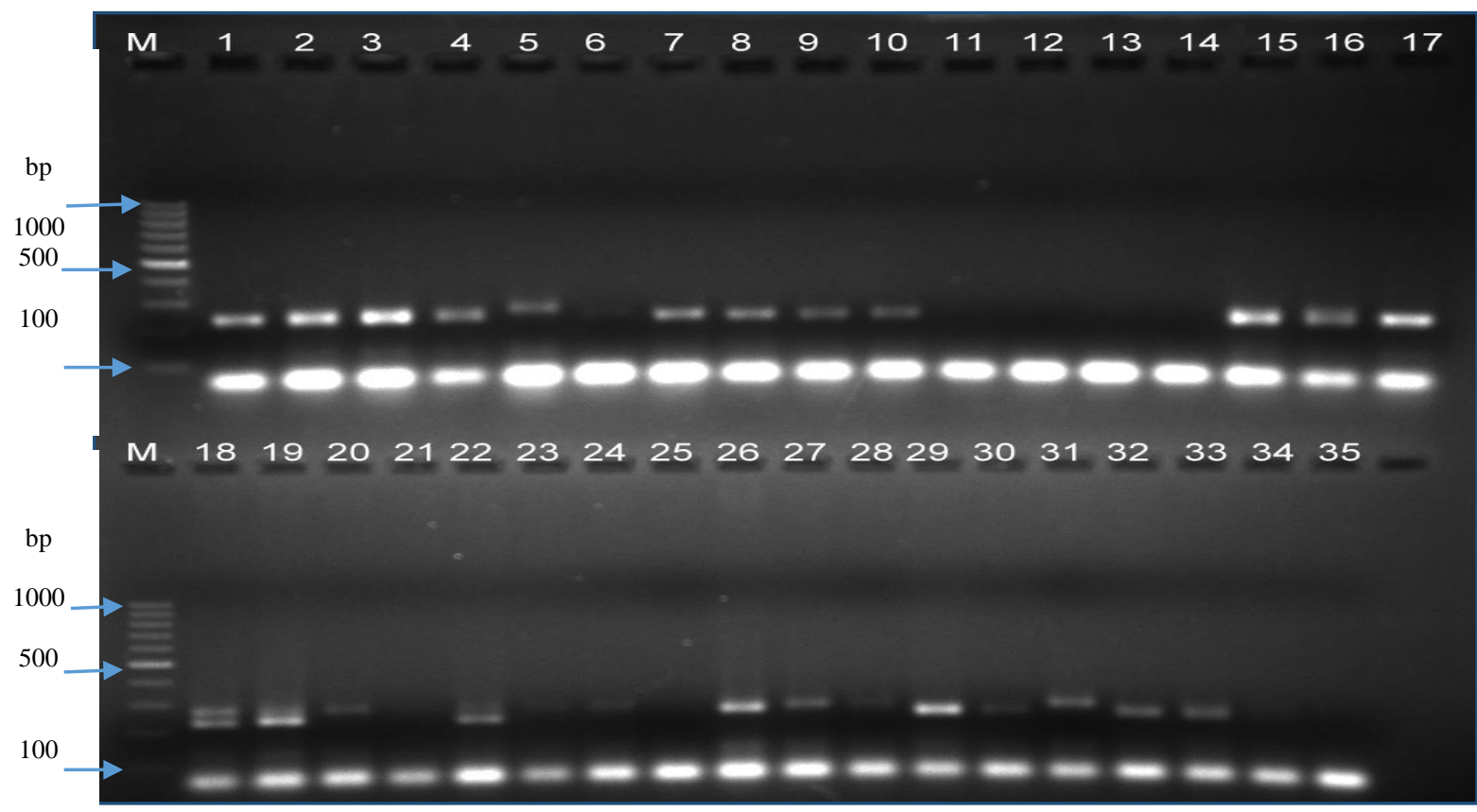

Figure 10: SSR Profile of 35 soybean accessions obtained with primer Sat-273

\begin{tabular}{|l|l|l|l|l|l|l|}
\hline 1.MAUS 01 & 6.cat872B & 11.cat34681 & 16.VLS-75 & 21.cat2130B & 26.cat3447 & 31.MAUS158 \\
\hline 2.MAUS02 & 7.cat2115B & 12.Harder & 17.cat1641A & 22.cat2134A & 27.cat3502 & 32.AGS-25 \\
\hline 3.MAUS32 & 8.cat2237B & 13.JS-93-05 & 18.cat1921A & 23.RI60cat2205B & 28.cat700A & 33.PP-6 \\
\hline 4.MAUS61 & 9.cat3458 & 14.JS-335 & 19.1979A & 24.cat3442 & 29.cat489A & 34.LEE-54 \\
\hline 5.MAUS162 & $\mathbf{1 0 . c a t 3 4 5 9}$ & $\mathbf{1 5 . G - 1 1}$ & $\mathbf{2 0 . c a t 1 9 8 7}$ & $\mathbf{2 5 . c a t 3 4 4 3}$ & 30.cat492A & 35.Glycine soja \\
\hline
\end{tabular}

\section{M - 100 bp DNA ladder Lanes: 1 to 35 (Soybean accessions)}




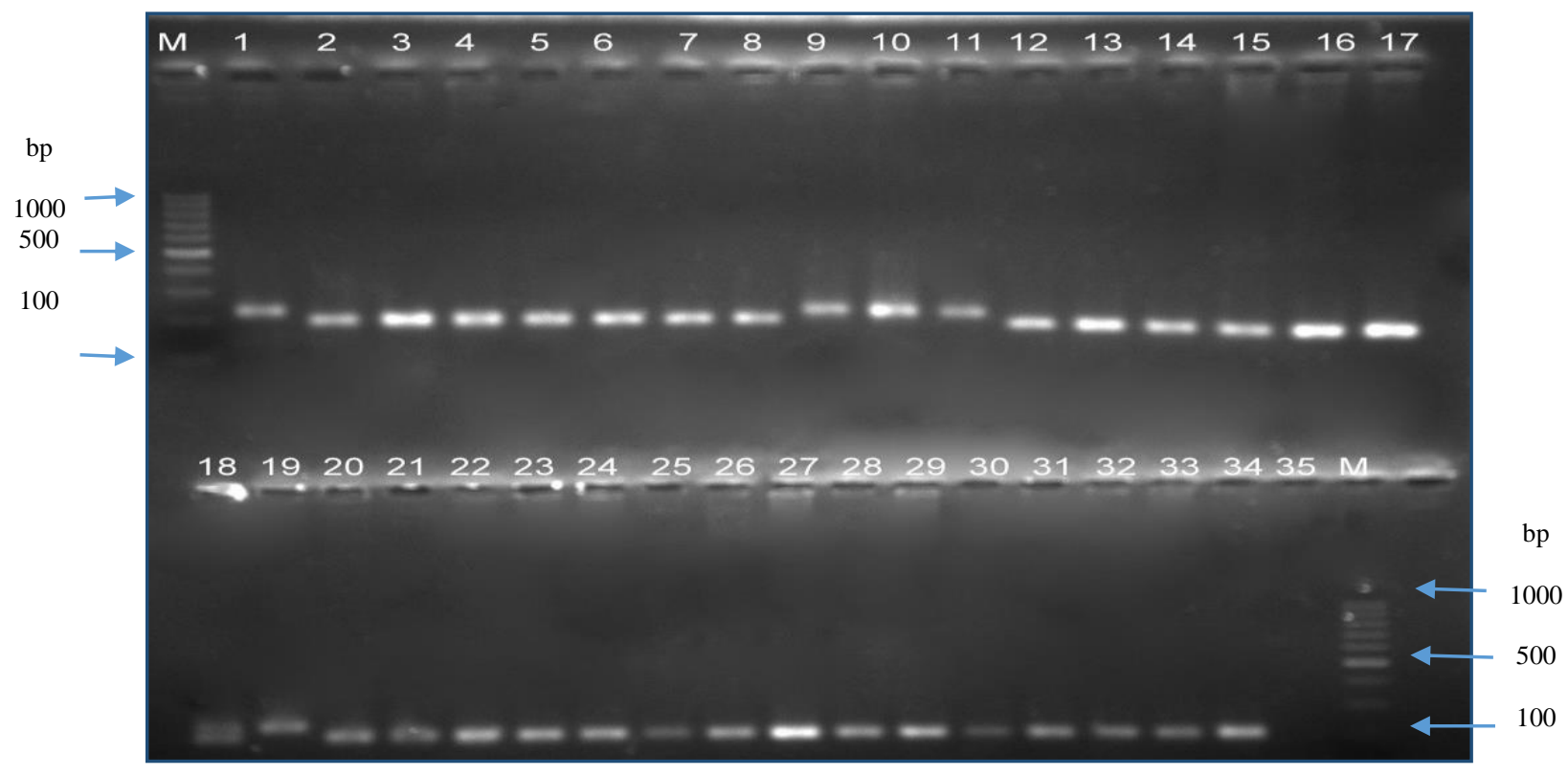

Figure 11: SSR Profile of 35 soybean accessions obtained with primer Satt285

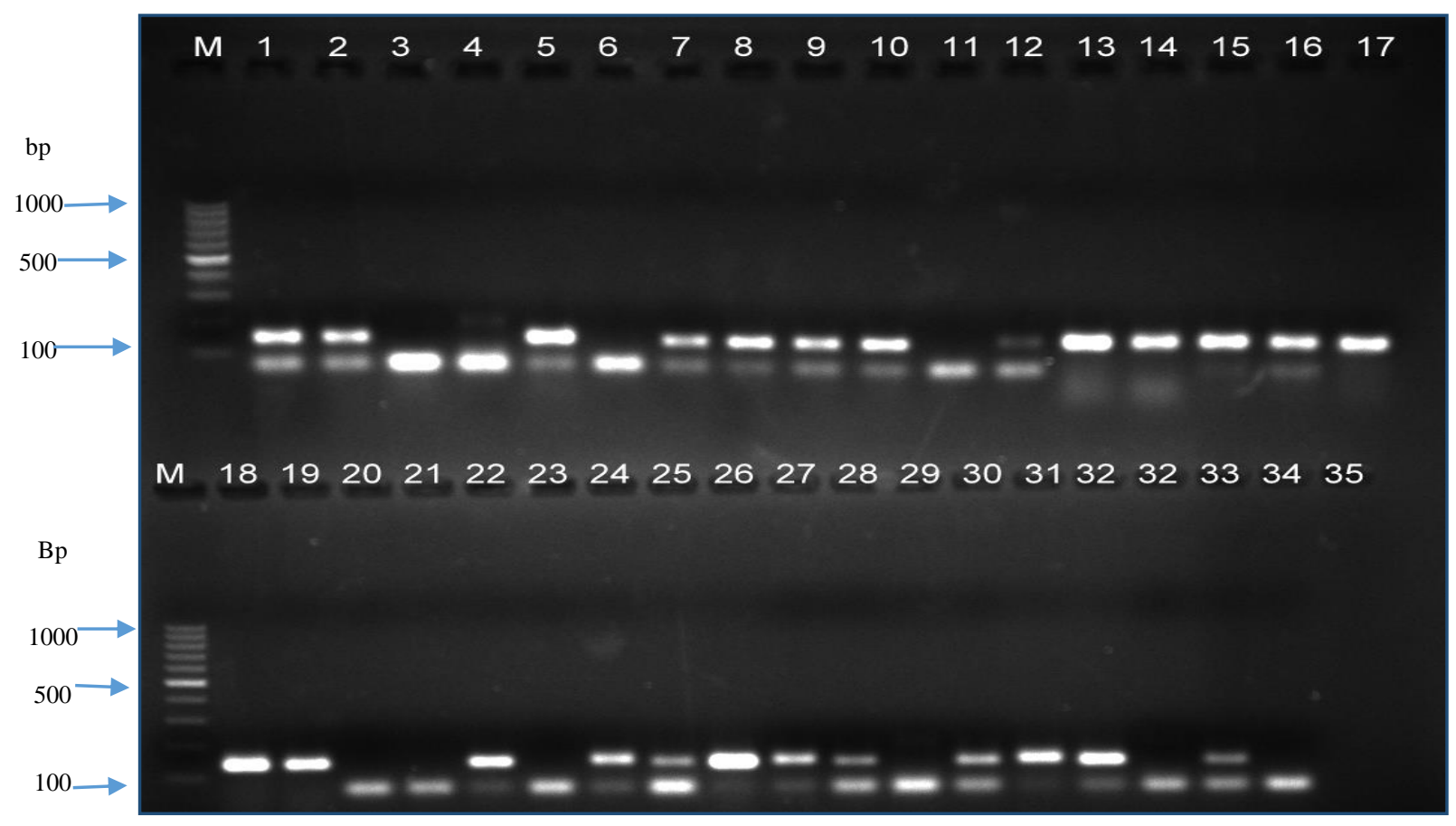

Figure 12: SSR Profile of 35 soybean accessions obtained with primer Sat_396

\begin{tabular}{|l|l|l|l|l|l|l|}
\hline 1.MAUS 01 & 6.cat872B & 11.cat34681 & 16.VLS-75 & 21.cat2130B & 26.cat3447 & 31.MAUS158 \\
\hline 2.MAUS02 & 7.cat2115B & 12.Harder & 17.cat1641A & 22.cat2134A & 27.cat3502 & 32.AGS-25 \\
\hline 3.MAUS32 & 8.cat2237B & 13.JS-93-05 & 18.cat1921A & 23.RI60cat2205B & 28.cat700A & 33.PP-6 \\
\hline 4.MAUS61 & 9.cat3458 & 14.JS-335 & 19.1979A & 24.cat3442 & 29.cat489A & 34.LEE-54 \\
\hline 5.MAUS162 & 10.cat3459 & 15.G-11 & 20.cat1987 & 25.cat3443 & 30.cat492A & 35.Glycine soja \\
\hline \multicolumn{7}{r|}{ M - 100 bp DNA ladder Lanes: 1 to 35 (Soybean accessions) } \\
\hline
\end{tabular}




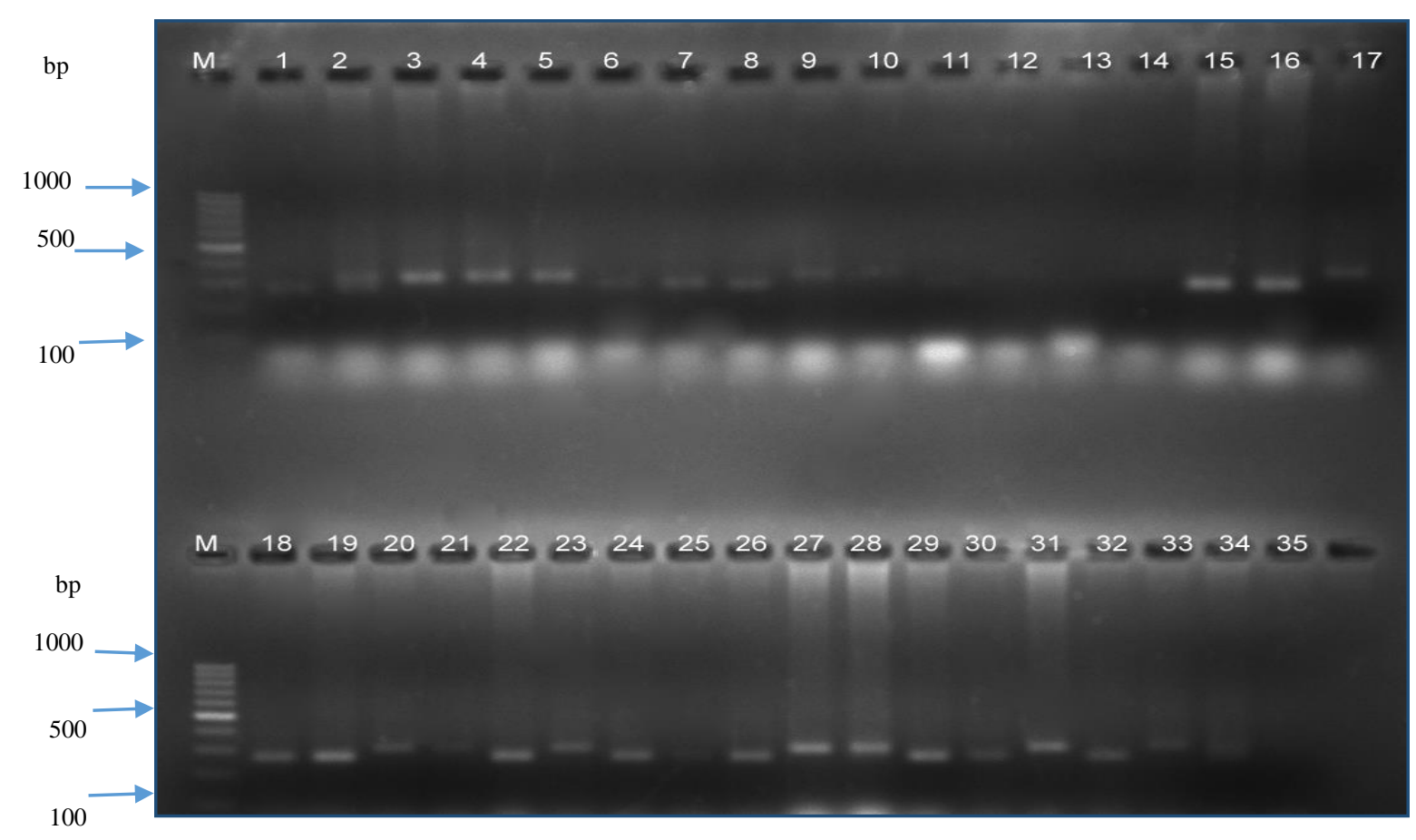

Figure 13: SSR Profile of 35 soybean accessions obtained with primer Satt385

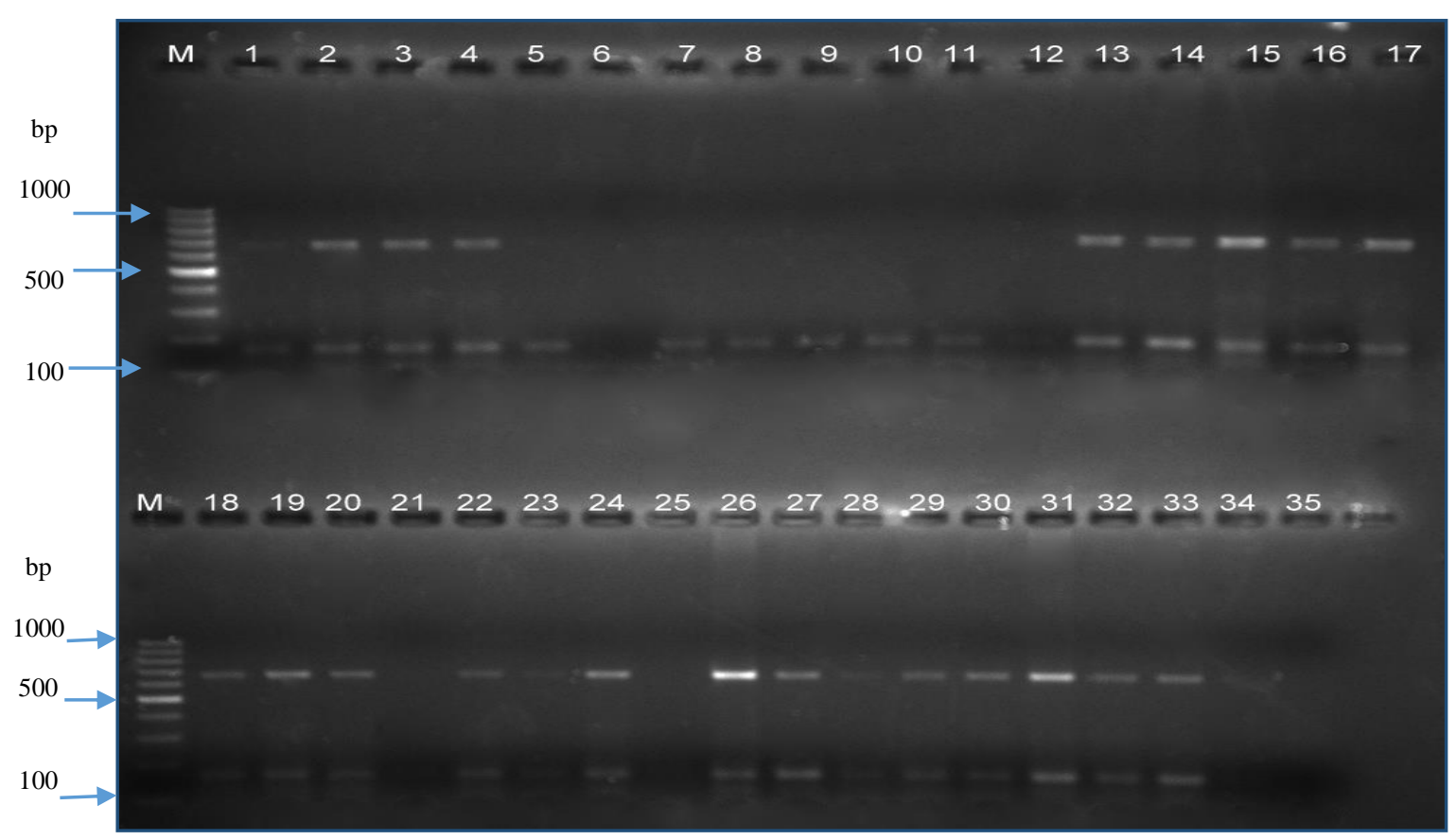

Figure 14: SSR Profile of 35 soybean accessions obtained with primer Satt126

\begin{tabular}{|l|l|l|l|l|l|l|}
\hline 1.MAUS 01 & 6.cat872B & 11.cat34681 & 16.VLS-75 & 21.cat2130B & 26.cat3447 & 31.MAUS158 \\
\hline 2.MAUS02 & 7.cat2115B & 12.Harder & 17.cat1641A & 22.cat2134A & 27.cat3502 & 32.AGS-25 \\
\hline 3.MAUS32 & 8.cat2237B & 13.JS-93-05 & 18.cat1921A & 23.RI60cat2205B & 28.cat700A & 33.PP-6 \\
\hline 4.MAUS61 & 9.cat3458 & 14.JS-335 & 19.1979A & 24.cat3442 & 29.cat489A & 34.LEE-54 \\
\hline 5.MAUS162 & 10.cat3459 & 15.G-11 & 20.cat1987 & 25.cat3443 & 30.cat492A & 35.Glycine soja \\
\hline \multicolumn{7}{|c|}{ M - 100 bp DNA ladder Lanes: 1 to 35 (Soybean accessions) } \\
\hline
\end{tabular}




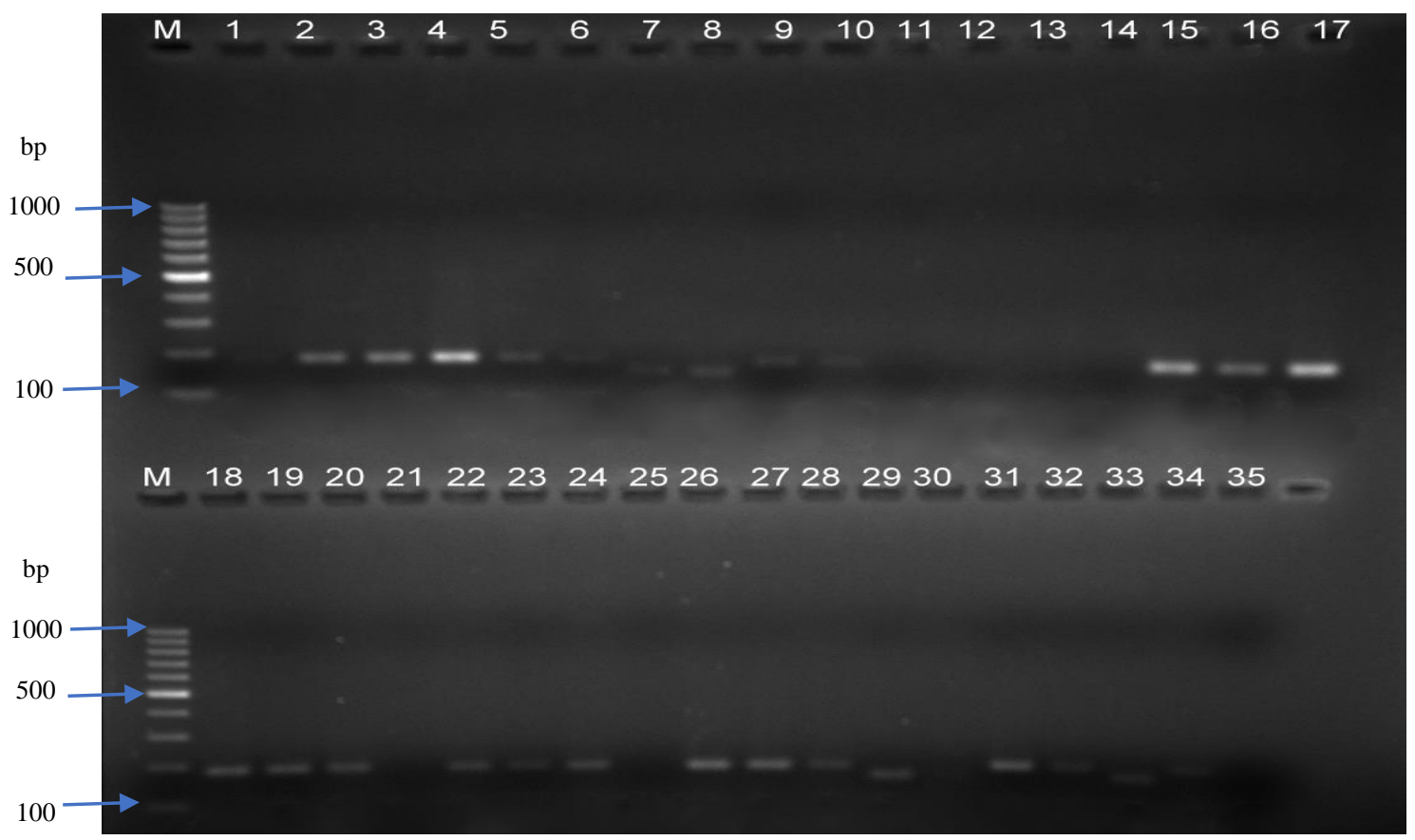

Figure 15: SSR Profile of 35 soybean accessions obtained with primer SRM2

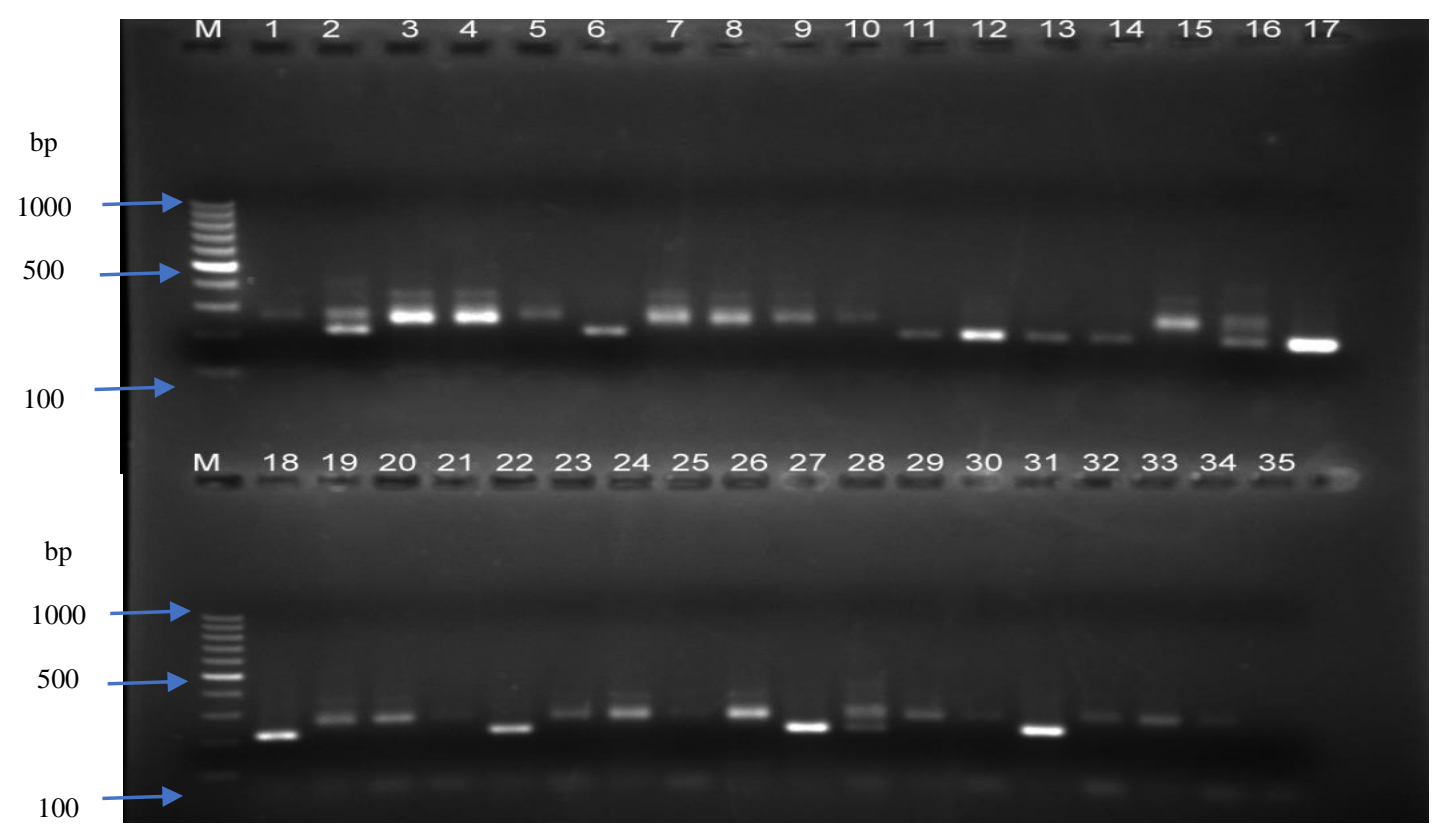

Figure 16: SSR Profile of 35 soybean accessions obtained with primer Satt166

\begin{tabular}{|l|l|l|l|l|l|l|}
\hline 1.MAUS 01 & 6.cat872B & 11.cat34681 & 16.VLS-75 & 21.cat2130B & 26.cat3447 & 31.MAUS158 \\
\hline 2.MAUS02 & 7.cat2115B & 12.Harder & 17.cat1641A & 22.cat2134A & 27.cat3502 & 32.AGS-25 \\
\hline 3.MAUS32 & 8.cat2237B & 13.JS-93-05 & 18.cat1921A & 23.RI60cat2205B & 28.cat700A & 33.PP-6 \\
\hline 4.MAUS61 & 9.cat3458 & 14.JS-335 & 19.1979A & 24.cat3442 & 29.cat489A & 34.LEE-54 \\
\hline 5.MAUS162 & $\mathbf{1 0 . c a t 3 4 5 9}$ & 15.G-11 & 20.cat1987 & 25.cat3443 & 30.cat492A & 35.Glycine soja \\
\hline
\end{tabular}

$$
\text { M - } 100 \text { bp DNA ladder Lanes: } 1 \text { to } 35 \text { (Soybean accessions) }
$$




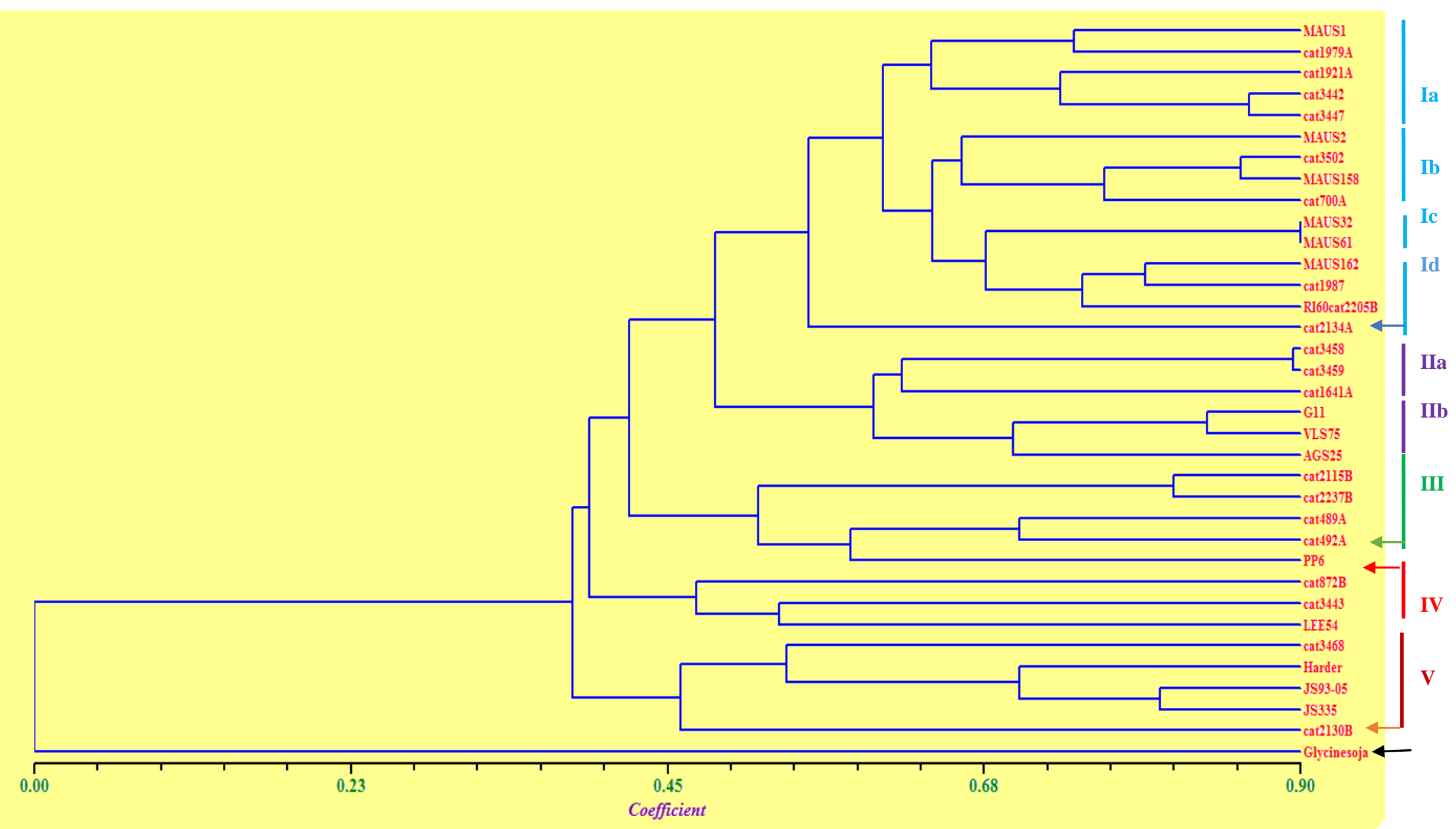

Figure 17 UPGMA dendrogram for the 35 soybean accessions based on PD-linked SSR analysis using Jaccard's similarity coefficient (NTSYSv2.02i, Rohlf, 2000)

$\longleftarrow$ Outgrouped genotype within/ outside cluster 